\title{
Is sexting bad for adolescent girls' psychological well- being? A longitudinal assessment in middle to late adolescence
}

Burić, Jakov; Garcia, Justin R; Štulhofer, Aleksandar

Source / Izvornik: New Media \& Society, 2020, -

Journal article, Accepted version

Rad u časopisu, Završna verzija rukopisa prihvaćena za objavljivanje (postprint)

https://doi.org/10.1177/1461444820931091

Permanent link / Trajna poveznica: https://urn.nsk.hr/urn:nbn:hr:131:085737

Rights / Prava: Attribution-NonCommercial-NoDerivatives 4.0 International/ImenovanjeNekomercijalno-Bez prerada 4.0 međunarodna

Download date / Datum preuzimanja: 2023-04-26

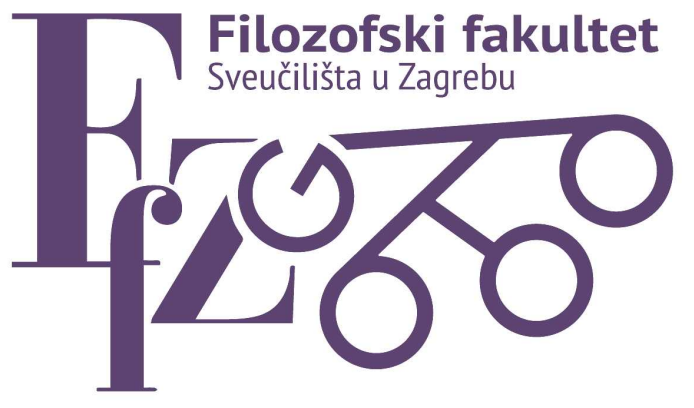

Repository / Repozitorij:

ODRAZ - open repository of the University of Zagreb

Faculty of Humanities and Social Sciences
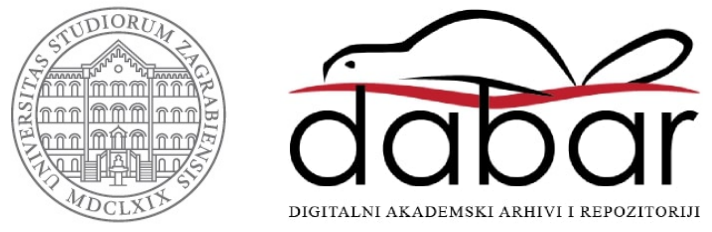


\title{
Is Sexting Bad for Adolescent Girls' Psychological Well-Being? A Longitudinal Asses....ent in Middle to Late Adolescence
}

\author{
Jakov Burić ${ }^{1}$ \\ Justin R. Garcia ${ }^{2,3}$ \\ Aleksandar Štulhofer ${ }^{4}$ \\ ${ }^{1}$ Center for Health Care St. Rok, Zagreb, Croatia \\ ${ }^{2}$ The Kinsey Institute, Indiana University, Bloomington, USA \\ ${ }^{3}$ Department of Gender Studies, Indiana University, Bloomington, USA. \\ ${ }^{4}$ Department of Sociology, Faculty of Humanities and Social Sciences, University of Zagreb, \\ Zagreb, Croatia
}

Short title: Female Adolescents' Sexting and Psychological Well-Being

\section{Address correspondence to:}

Aleksandar Štulhofer, PhD

Department of Sociology, Faculty of Humanities and Social Sciences

University of Zagreb

10000 Zagreb, Croatia

E-mail: astulhof@ffzg.hr

Funding source: The study has been funded by the Croatian Science foundation (grant \#9221 awarded to the last author. 


\begin{abstract}
Sexting, the digital transmission of sexual messages and images, has become a topic of increased interest and concern. Drawing largely on cross-sectional studies, the literature on associations between sexting and psychosocial outcomes remains inconsistent. The current longitudinal study investigated associations between adolescent girls' sexting and two indicators of psychological well-being: symptoms of depression/anxiety and self-esteem. Responses were collected from a panel sample of 859 female Croatian secondary-school students over a 20-month period, across five classroom-based data collection points. Multi-domain latent growth curve modeling indicated that sexting dynamics were unrelated to changes in psychological well-being. Adverse family environment and, to a lesser extent, participants' peer conformism were related to more frequent sexting and lower levels of psychological well-being. Our findings support the notion that in general adolescent girls' sexting may be a (non-pathological) part of sexual development during middle to late adolescence in today's digital age.
\end{abstract}

Key Words: Adolescence; sexting; psychological well-being; computer-mediated communication 


\section{Is Sexting Bad for Adolescent Girls' Psychological Well-Being? A Longitudinal Assessment in Middle to Late Adolescence}

\section{INTRODUCTION}

There is ongoing debate among scholars and the public about whether sexting-defined as sending and/or receiving sexually suggestive texts, photos, or videos typically of oneself (Drouin, 2017; Klettke, Hallford, \& Mellor, 2014)—poses a threat to adolescent psychological development and well-being. With several cases of sexting resulting in widespread attention, including a few occasions of adolescent sexting that invoked regional child pornography laws, as well as incidents where a young victim of leaked sexts subsequently committed suicide, the public has raised legitimate concerns about negative consequences of such behavior (see O'Connor, Drouin, Yergens, \& Newsham, 2017). Two prominent discourses have emerged in discussions around youth sexting behavior. The first, which is seemingly more prevalent and has recently received some meta-analytic support (Mori et al., 2019), frames sexting as deviant and risky behavior (see Döring, 2014)—which may lead to decreased well-being through, for example, sexting-triggered online harassment (Festl et al., 2019). This perspective has at times been framed as a moral panic (Angelides, 2013) that seems to focus on adolescent girls, with justification ranging from the imperative to protect vulnerable minors from sexual abuse and exploitation to the framing of girls' sexual expression as inherently problematic (Hasinoff, 2013). In contrast, the second discourse portrays sexting as a more or less normative form of sexual expression in today's digital age, which includes developmentally-specific exploration of sexuality among adolescents (Kosenko et al., 2017).

Sexting-associated risks may be greater for marginalized groups (Currin et al., 2016; Van Ouytsel et al., 2019), including adolescent girls, whose gender socialization often makes them 
particularly susceptible to negative consequences of sexuality-related peer pressure and social evaluation (Tolman, 2002). Yet, as one recent meta-analysis on sexting noted, there has been a surprising absence of attention to sexual and gender identity in the existing sexting literature (Kosenko et al., 2017), making socio-demographic differences difficult to decipher. Despite this, some recent findings indicate that adolescent girls, compared to adolescent boys, are more likely to receive pressure to sext while simultaneously being negatively evaluated for engaging in sexting (Lippman \& Campbell, 2014). Research on UK teens by Ringrose and colleagues (2013) argues that sexual double standard norms explain why girls, but not boys, are stigmatized and shamed for taking and sharing sext images.

Considering the mixed findings and predominantly cross-sectional nature of the existing research on sexting - which is reflected in a recent call for more longitudinal research (Mori et al., 2019) - and the need for greater focus on outcomes specific to young women, the current study sought to longitudinally explore links between adolescent girls' sexting and psychological well-being.

\section{Adolescent Sexting: Prevalence and Motives}

Several studies have reported on the prevalence of sexting behaviors, ranging anywhere from $4-80 \%$ (Klettke et al., 2014). This wide sexting prevalence range primarily reflects the diversity of conceptual, sampling, and measurement approaches to the phenomenon. Previous studies have been predominantly North American focused, with fewer sexting studies conducted on European samples of adolescents (for recent examples see Bianchi et al., 2019; Gámez-Guadix \& Mateos-Pérez, 2019). One study carried out in 2009 on a representative sample of 3,432

adolescents in Sweden revealed that $4.3 \%$ of the sample posted sexual pictures online (Jonsson et al., 2015). In a more recent large-scale Spanish sample of 1,497 12-14 year-olds, the proportion of participants who engaged in sexting during the last year was notably larger at 7.6\% (Gámez- 
Guadix and Mateos-Pérez, 2019). Further, in a sample of 1,028 Belgian adolescents (mean age in the sample was 16.7 years) $11.1 \%$ of participants reported sexting (Van Ouytsel, Van Gool, Ponnet, \& Walrave, 2014). Yes, in a large-scale European study conducted among a sample of 18,709 adolescents, the average proportion of adolescents that engaged in sexting was $3.4 \%$ (Baumgartner et al., 2014).

The relative popularity of sexting among adolescents may be explained by their heavy use of computer-mediated communication more broadly, along with their perception of sexting as a relatively risk-free form of erotic and intimate communication (Strassberg et al., 2013). Considering the former aspect, research shows that new communication technologies play a crucial role in adolescents' lives across cultures. The use of mobile media, Internet, and online social networking sites has been found to be essential for adolescent self-expression and identity, behavior modeling, peer support, learning, entertainment, pleasure, and also risk taking (Best et al., 2014; Festl et al., 2019; Montgomery et al., 2020). Accordingly, sexting may be viewed as the continuation of teenagers' sexual exploration by digital means or, as suggested by Hasinoff (2013), as a primarily positive process of youth media creation based on sexual self-expression.

Several motives for sexting have been proposed by researchers and clinicians, such as maintaining intimacy within a relationship or flirting as a means of attracting the attention of a potential romantic or sexual partner (Englander, 2012; Henderson, 2011). Sexting may also be part of an experimental phase of sexual and gender development, or the result of pressure from partners or friends (Bianchi, Morelli, Baiocco and Chirumbolo, 2019; Cooper et al., 2016). Although some adolescents may use sexting for initiating sex with casual partners, existing research demonstrates that it occurs predominantly between romantic partners (Garcia et al., 2016; Klettke et al., 2014). In addition, motivation for sexting can also include the construction and/or reinforcement of body image, particularly among sexual minority youth, and, less 
frequently, may occur for material/financial reasons (Bianchi, Morelli, Baiocco and Chirumbolo, 2019). These varying motives are not mutually exclusive and speak to multiple factors that influence young people's sexuality.

In the context of adolescent sexuality, sexting potentially provides a confidential space for sexual experimentation and intimate self-disclosure. Similar to eroticized self-presentation on online social networking sites, sexting may be largely motivated—particularly among adolescent girls (van Oosten and Vandenbosch, 2017) — by striving for peer popularity (adolescents seem to believe that popular peers sext; Maheux et al., 2020) or by emotional and/or erotic interest for the recipient of sexts. Taking into account the existence of sexual double standards (Albury, 2015; Symons et al., 2018), which places a particularly heavy burden on the maintenance of social reputation on adolescent girls and young women, sexting enables safer and less restricting sexual exploration than offline sexual activity. This is likely reflected in the mostly positive emotions associated with the practice in a large-scale sample of Spanish high-school students (Rey et al., 2019).

\section{Sexting, Psychological Well-Being, and Gender}

Considering associations between sexting and worrisome aspects of sexual and nonsexual behaviors (Kosenko et al., 2017) — such as early sexual initiation and risky sexual behaviors (Benotsch et al., 2013; Dir et al., 2013), as well as alcohol and recreational drug use (Dake et al., 2012; Dir et al., 2013)—some scholars have investigated connections between sexting and a number of psychological well-being indicators, such as self-esteem, negative mood, and suicidality. For example, in a sample of 1,289 adolescents, Dake and colleagues (2012) found that sexting was related to higher odds of reporting symptoms of depression, having planned suicide, or having been a victim of online bullying. In another study of at-risk adolescents, sexting was associated with problems in regulating emotions (Houck et al., 2014). Pointing to a 
complex directionality, Van Ouytsel, Walrave, Ponnet, and Heirman (2015) argued that sexting might be indicative of psychosocial problems and may reflect poor emotional functioning, particularly under peer or partner pressure (see Van Ouytsel, Van Gool, Ponnet, \& Walrave, 2014).

In contrast, Temple et al. (2014) found no association between sexting and depression and anxiety symptoms in a cross-sectional study carried out among 937 adolescents. Another study of college students observed no differences in self-esteem between participants who reported sexting and those who did not (Hudson and Fetro, 2015). The authors proposed that sexting is used by young adults characterized with low, as well as with high self-esteem — but for different reasons. The former may sext because their partner pressured them into it, while the latter may engage in sexting to reward their partner. A large-scale cross-sectional study conducted among 3,447 emerging adults revealed no association between sexting and depression, anxiety, or selfesteem, suggesting that mental health issues are not more frequent among those who sext than those who do not (Gordon-Messer et al., 2013).

Gender and feminist scholars have noted that young women, compared to young men, face unique challenges around issues of gender and sexual development and expression (Orenstein, 2016). Girls tend to face a double bind; compared to boys, they are both more sexualized by peers and society, and more likely to be socially punished for being sexual (see Conley, Ziegler, \& Moors, 2013 and Tolman, 2002). For example, a qualitative study of adolescents found that female, but not male, adolescents reported being judged harshly for engaging, but also for not engaging, in sexting (Lippman \& Campbell, 2014). Further, adolescent girls may be more exposed to sexting-related cyberbullying, blackmail, and/or public shaming (Lippman \& Campbell, 2014; West et al. 2014). All this may manifest in adverse psychological outcomes, which is especially troubling given that girls and young women are more likely to 
report negative mental health outcomes such as higher rates of depression than their male peers (Kuehner, 2017; Mojtabai et al., 2016).

\section{Parental and Peer Influence}

According to Ecological Systems Theory (Bronfenbrenner, 1989), adolescents' development is influenced and shaped by several interdependent systems - most notably, by their family environment and by peer influence. In the context of adolescent sexual behavior, studies have demonstrated a protective role of open communication about sexuality with one's parents in sexual initiation and sexual risk-taking (de Graaf et al., 2012; Deptula et al., 2010). Moreover, it has been shown that positive parenting (characterized by open communication, encouragement, and emotional support) is associated with good peer relationships and resistance to negative peer influence (Boutakidis and Lieber, 2017; Caprara et al., 2002; Mounts, 2002). Using a longitudinal design, a recent Croatian study pointed to a positive role of parental support in female adolescents' sexual agency, or the capability to enact one's sexual wishes, communicate personal expectations and boundaries, and feel entitled to sexual pleasure (Klein et al., 2018).

Inadequate parenting and a problematic family environment, on the other hand, may have the opposite effect. In a longitudinal study that followed over 12,000 adolescents, poor family relationships were related to greater exposure to peer pressure (Sullivan, 2006). Furthermore, a problematic family environment may enhance peer conformism and influence adolescents to prioritize peer popularity in order to find recognition and support, which in turn may increase peer-approved risk taking and/or norm-violating behaviors (Brechwald and Prinstein, 2011).

One large-scale cross-sectional study of Croatian adolescents found that parental monitoring significantly predicted levels of sexual experience, sexting, and self-reported sexual aggressiveness in both male and female adolescents (Tomić et al., 2018). Compatible findings were reported in an Italian study of female adolescents, where communication in the family 
strongly and negatively predicted participants' engaging in sexting (Bianchi, Morelli, Baiocco, Cattelino, et al., 2019).

The influence of peers has been well-documented in the context of adolescents' and emerging adults' intentions to engage in, or avoid, sexting (Hudson and Fetro 2015; Vanden Abeele et al. 2014; Walrave, Heirman, and Hallam 2014). A recent study that focused on associations between sexting and peer network characteristics found that the frequency of adolescent sexting was related to the proportion of same-sex, older, and sexually experienced peers in one's network, regardless of the participant's gender (Lucić et al., 2019). Considering that peer conformity is more readily expected of adolescent girls than boys, particularly in the context of romantic relationships, peer pressure may be particularly salient for female adolescents and emerging adults. Indeed, over half of adolescent girls (51\%) included in the National Campaign to Prevent Teen and Unplanned Pregnancy 2008 study reported being pressured into sexting by their partner. This is particularly relevant in light of research demonstrating links between coerced sexting and adverse mental health outcomes (Drouin, Ross, \& Tobin, 2015).

\section{Current Study}

The aim of the current study was to assess the relationship between adolescent girls' sexting and psychological well-being, indicated by self-esteem and the absence of internalizing problems (i.e., depression and anxiety symptoms), over a period of approximately 20 months that mark the transition from middle to late adolescence. Although some studies have found a negative association between sexting and psychological well-being (e.g., Dake et al., 2012; Van Ouytsel et al., 2014), the lack of longitudinal studies hinders reliable conclusions, as emphasized in two recent meta-analyses. Of the 15 reviewed studies by Kosenko and colleagues (2017), only one employed a longitudinal design; a more recent meta-analysis of 23 studies that met inclusion criteria only one was longitudinal (Mori et al., 2019). 
The age period assessed in the current study aligns with the timing of when a majority of adolescent girls become sexually active (mean age at first sexual intercourse among emerging Croatian female adults in 2010 was 17.4 years; Landripet, Štulhofer, \& Baćak, 2011). Due to conflicting findings in the literature, we decided against positing a hypothesis that would specify the direction of correlation between the key constructs. Instead, we focused on the following exploratory research questions: (1) Is sexting associated with Croatian adolescent girls' psychological well-being over time and, in the case of significant finding, (2) is this relationship positive or negative?

To provide sociocultural context for this study, we note that adolescent life in Croatia is marked by relative sexual permissiveness and gender role egalitarianism, particularly in urban areas (Marinović Jerolimov \& Ančić, 2014). Although a trend of increasing religiosity has been observed - Croatia, one of the most religious countries in the European Union (Luijkx, R., Halman, L., Sieben, I., Brislinger, E., \& Quandt et al., 2016), is predominantly Roman Catholic)—including among young people (Marinović Jerolimov and Jokić, 2010), there is little evidence that youth sexual behavior has been substantially affected by these dynamics (Puzek et al., 2012; Štulhofer et al., 2011). Considering computer-mediated communication technologies, already in $200891 \%$ of urban adolescents reported access to the Internet. According to findings from a recent European study, 66\% of Croatian adolescents $15-16$ years were daily accessing Internet using their smartphone. Among adolescent girls, mean time spent online was 205 minutes a day (Smahel et al., 2020).

\section{METHOD}

\section{Participants}

A panel sample of high-school sophomores $\left(M_{\mathrm{age}}\right.$ at baseline $\left.=15.8, \mathrm{SD}=.50\right)$ was used in this study. Male and female adolescents were recruited from 14 larger secondary schools in 
Rijeka, the third largest city in Croatia (for more details, see $* * *$ blinded for review $* * *$ ). In the current study, we only present responses from adolescent girls. The initial survey $\left(\mathrm{T} 1, n_{\text {females }}=\right.$ 763) took place in December 2015 and was repeated in April 2016 (T2, $\left.n_{\text {females }}=743\right)$, October $2016\left(\mathrm{~T} 3, n_{\text {females }}=742\right)$, April $2017\left(\mathrm{~T} 4, n_{\text {females }}=713\right)$, and October $2017\left(\mathrm{~T} 5, n_{\text {females }}=582\right)$. The notable decrease in participation observed at $\mathrm{T} 5$ was due to the fact that students enrolled in 3-year vocational programs finished their secondary education about a month after T4. Data cleaning resulted in a small number of questionnaires being excluded for gross inconsistencies, illogical and/or humorous responses. Panel attrition among female participants appeared to primarily reflect school absenteeism, which was also responsible for new participants entering the panel after T1. In addition to absenteeism, the sample size was also affected by difficulties in linking some personal codes. After written instructions for generating the 5-digit code were revised at $\mathrm{T} 3$, the average number of unlinked questionnaires at $\mathrm{T} 4$ and $\mathrm{T} 5$ was substantially reduced.

To address possible biases introduced by attrition, multivariate logistic regression analysis was carried out to compare female participants who participated in all five study waves and those who did not. Independent variables were sociodemographic indicators (age, father's and mother's education, family type, religiosity, academic achievement and type of secondary school attended) and baseline levels of the three key indicators explored in this study (sexting, depression/anxiety, and general self-esteem). Compared to their peers, adolescent girls who participated in all five waves were characterized by higher academic achievement $(\mathrm{AOR}=1.40, p<.05)$. No other differences between the two groups were observed.

The majority of participants in the current study (76.8\%) were living with both parents at the time of the survey. Having a college educated father was reported by $33.2 \%$ and a college educated mother by $33.8 \%$ of students, which indicates that participants' parents were somewhat 
more educated than the national average. Less than a third of participants $(30.7 \%)$ were enrolled in a high-school (gymnasium), which prepares for tertiary education, while the rest attended a less prestigious 3- or 4-year vocational school. No religious attendance was acknowledged by $15.4 \%$ of adolescent girls, while $28.0 \%$ reported a monthly or more frequent attendance. At baseline, a fifth of participants (20.2\%) acknowledged the experience of sexual intercourse.

\section{Procedure}

Self-administered paper-and-pencil survey, which took 20-30 minutes to complete, was used to collect data in classrooms. Large portable screens were placed between participants to maximize confidentiality. Information required for students' consent was delivered by one of the research assistants responsible for data collection and also included at the beginning of the questionnaire. In the case that participation triggered concerns or negative feelings, contact information for a youth psychological health center was provided at the end of the questionnaire.

The study was approved by the Ministry of Science and Education, the Office for Ombudsman for Children, and principals of all 14 schools included. Prior to the study launch, all parents were sent a leaflet with basic information about this longitudinal study. According to the national guidelines on ethical research in minors (Kolesarić and Ajduković, 2003), the study required only passive parental consent. No incentives were provided for participation. All study procedures were approved by the Committee on Ethics and Research of the Faculty of Humanities and Social Sciences, University of [blinded] (2014; protocol title "Prospective biopsychosocial study of the effects of sexually explicit material on young people's sexual socialization and health").

\section{Measures}

Sexting was a summative scale composed of three items asking about the number of times in the past six months that the participant had sent a sexual message, sexy photograph, or sexy 
video clip of oneself to someone. A five-point scale, ranging from $1=$ not once to $5=6$ or more times, was used to anchor answers. Principal component analysis with parallel analysis as the method for estimating the number of factors confirmed that the measure was unidimensional across study waves; the three items formed a single latent construct with loadings in the .63-.88 range. The composite indicator had acceptable internal consistency at each data collection point (Cronbach's $\alpha$ ranged from .65-.79) and, developmentally meaningful, moderate 6-month stability (zero-order correlation coefficients ranged from .69 to .43).

Psychological well-being was indicated by self-esteem and (the absence of) depression and anxiety symptoms. General self-esteem was assessed by four items (e.g., In general, I like myself the way I am and When I do something, I do it well) from a recent longitudinal study of Canadian teenagers (Cénat et al., 2014). A Likert-like scale, ranging from $1=$ it doesn't relate to me at all to $5=$ it completely relates to me, was used to record responses. The composite scale was characterized by satisfactory reliability (Cronbach's $\alpha=.81-.83$ ) and 6-month stability (ranging from $r=.74$ to .62 ).

The Patient Health Questionnaire for Depression and Anxiety (PHQ-4; Kroenke, Spitzer, Williams, \& Lowe, 2009), a brief 4-item scale (e.g., Feeling nervous, anxious or on edge and Little interest or pleasure in doing things), was used to assess symptoms of depression (2 items) and anxiety ( 2 items) experienced in the two weeks preceding the survey. Although distinct, these two constructs have been found to substantially overlap in youth (Schleider and Weisz, 2017; Stark and Laurent, 2001). The frequency of symptoms was indicated using a 4-point scale that ranged from $1=$ not at all to $4=$ nearly every day. The composite indicator had good reliability (Cronbach's $\alpha=.83-.85$ ) and reasonable 6-month test-retest reliability (stability coefficients ranged from .64 to .47 ) in this study. 
Peer and parental influences were treated as controls. Striving for peer popularity was measured only at baseline, using four items (e.g., At times, I've broken rules because others have urged me to and I have done things to make me more popular, even when it meant doing something I would not usually do) adapted from the Peer Pressure and Popularity Scales developed in a sample of early adolescents (Santor et al., 2000). Responses were noted on a Likert-like 5-point scale ranging from $1=$ it doesn't relate to me at all to $5=$ it completely relates to me. The indicator had satisfactory reliability (Cronbach's $\alpha=.76$ ). Adverse family environment was measured at baseline, T3 and T5 by three items that asked about the frequency of intense quarrels, aggressive behaviors (shoving or slapping someone, deliberately breaking things) and family members systematically ignoring each other in the past 12 months. These three items were developed for this study and piloted in a sample of high-school students. A 5point scale ranging from $1=$ never to $5=$ often was used to anchor answers. The measure had acceptable internal consistency (Cronbach's $\alpha=.72)$ and temporal stability ( $r=.49$ to .61 ). Taking into account that family environment characteristics was a time-varying indicator (measured at T1, T3, and T5), its values were averaged across time.

\section{Analytical Strategy}

Latent growth curve modeling (LGCM) was used to explore the association between sexting and adolescent psychological well-being. This method allows for the estimation of group (i.e., mean) changes over time (fixed effects), as well as individual differences in growth trajectories (random effects). Compared to traditional approaches to longitudinal data analysis, LGCM has several strengths including higher statistical power (Muthén and Curran, 1997), adequate handling of missing information, unequally spaced time points, and non-normally distributed measures (Curran et al., 2010). 
Here, we used 5-wave multi-domain or parallel process LGCM, with time expressed in months, to explore dynamic relationships between sexting and the two indicators of psychological well-being. Statistically, the relationships were represented by covariances among the constructs' intercept and slope factors. The analytical procedure was carried out in three steps. First, a linear and a non-specified cumulative (the first slope loading is fixed to 0 and the last one to 1; McArdle \& Grimm, 2010; Preacher, Wichman, MacCallum, \& Briggs, 2008) growth curves were fitted and compared. The standard chi-square difference test indicated that the cumulative curve specification was superior to the linear one in the cases of sexting and depression/anxiety, but not self-esteem.

Next, an unconditional multi-domain model was fitted to the data. Significant growth in individual trajectories of sexting, depression/anxiety and self-esteem was the precondition for all subsequent analyses. To control for potential confounders, a conditional multi-domain model with family environment and peer popularity as latent covariates was explored in the third and final step. Model fit was evaluated using $\chi^{2}$, TLI, CFI, and RMSEA statistics. Following standard guidelines (Byrne, 2010), TLI and CFI values $\geq .95$ and RMSEA values $\leq .05$ were considered to represent good fit.

Considering that $5.2 \%$ of values missing due to unanswered questions appeared to be missing completely at random (Little's MCAR test $\chi^{2}{ }_{(147)}=140.9, p=.627$ ), full information maximum likelihood (FIML) estimation was used to deal with missing data (Graham, 2012). Finally, to account for cluster-based sampling (participants were recruited in classes), the size of intra-class correlation (ICC) in the key indicators was estimated by linear mixed effects modeling prior to LGCM analyses. Nestedness in class accounted for $1.4 \%$ of variance in adolescent girls' sexting in Rijeka. Considering that a reasonably low ICC were also found in the case of selfesteem (5.6\%) and depression/anxiety (4.8\%), the effect of clustering was disregarded in LGCM. 


\section{RESULTS}

\section{Sample Characteristics}

A majority of the sampled students (61.0\%) reported no sexting at baseline. At the final wave (T5), the proportion was slightly higher (62.2\%), confirming that the practice remained characteristic of a minority of participants. On average, adolescent girls' sexting: $M_{\mathrm{T} 1}=4.27, \mathrm{SD}$ $=2.13, M_{\mathrm{T} 2}=4.06, \mathrm{SD}=2.05, M_{\mathrm{T} 3}=4.28, \mathrm{SD}=2.30, M_{\mathrm{T} 4}=4.35, \mathrm{SD}=2.44$. and $M_{\mathrm{T} 5}=4.52$, $\mathrm{SE}=2.59$, seemed to increase in non-linear fashion. Table 1 shows between-person level correlations between the three key constructs: sexting, depression and anxiety (i.e., internalizing problems) levels, and self-esteem. At bi-variate level, the frequency of sexting was consistently and positively associated with depression and anxiety symptoms. The relationship between sexting and self-esteem was mostly negative, but did not reach statistical significance.

\section{TABLE 1 ABOUT HERE}

\section{Associations Between Sexting, Depression/Anxiety, and Self-Esteem}

Unconditional multi-domain model fit the data well: $\chi^{2}(99)=263.5, \mathrm{TLI}=.96, \mathrm{CFI}=.97$, RMSEA $=.041(90 \% \mathrm{CI}=.035-.047)$. Average change over time was significant for all three constructs. While cumulative growth in sexting and linear growth in self-esteem were positive, indicating increase in the two constructs over time, cumulative growth in depression and anxiety was negative (Table 2). We also observed significant variation in individual starting points, as well as trajectories of change in the three constructs.

Next, structural associations were inspected. As shown in Figure 1, only one of eight associations between sexting and the indicators of psychological well-being was statistically significant - the link between frequency of sexting and internalizing problem levels at baseline, $r$ 
$=.24, \mathrm{SE}=.23, p<.001$. Unsurprisingly, relationships between internalizing problems and selfesteem were consistently significant and mostly negative.

TABLE 2 AND FIGURE 1 ABOUT HERE

To test the robustness of these findings, we repeated the LGC model with only those adolescent girls who participated in all five data collection waves $(n=348)$. The model had similar fit: $\chi^{2}{ }_{(99)}=198.7, \mathrm{TLI}=.96, \mathrm{CFI}=.97, \mathrm{RMSEA}=.054(90 \% \mathrm{CI}=.043-.065)$. The pattern of (non)significant paths remained identical to the original model, with a single exception: the path (i.e., covariance) connecting sexting at baseline and latent growth in depression/anxiety symptoms reached statistical significance $(\mathrm{p}<.001)$. The association was moderate and negative $(r=-.31, \mathrm{SE}=.31)$, indicating that higher baseline pornography use was related to lower growth in negative mood symptoms over time. Although this finding, as suggested by an anonymous reviewer, may reflect a possibility that adolescent girls characterized by more frequent sexting at baseline developed a more secure personality over time (sexting can help in establishing romantic relationships and exploring sexuality during adolescence), we decided to retain the model with all available information. This decision was based on statistical power considerations (the original LGC model used a sample more than twice as large than the one used for robustness check) and the fact that we observed no significant differences in baseline levels of sexting, self-esteem, and depression/anxiety between participants who participated in all and those who participated in only some of the study waves. Even more importantly, it rests on observations that the exclusion of participants who skipped one or more study waves can substantially bias estimations (Little, 2013), similar to the bias introduced by the exclusion of cases with missing information in crosssectional studies. 
Finally, to address possible confounding, the multi-domain model was repeated with two latent covariates included (i.e., adverse family environment, which was averaged across time, and striving for peer popularity at baseline). The pattern of (non)significant structural findings in this conditional model, which was also characterized by good fit: $\chi^{2}(205)=430.8, \mathrm{TLI}=.96, \mathrm{CFI}=.97$, RMSEA $=.033$, remained unchanged. Participants who reported a more adverse family climate over time were more likely to report more sexting, $\beta=.22, \mathrm{SE}=.16, p=000$, higher levels of depression and anxiety, $\beta=.35, \mathrm{SE}=.28, p=000$, and lower self-esteem at baseline, $\beta=-.19, \mathrm{SE}$ $=.23, p=001$. Problematic family environment was also linked to growth in the frequency of sexting over time, $\beta=.15, \mathrm{SE}=.18, p=049$, but not changes in depression and anxiety or selfesteem. Peer popularity was associated with baseline sexting, $\beta=.12, \mathrm{SE}=.10, p=.011$, and self-esteem, $\beta=-.14$, $\mathrm{SE}=.15, p=.002$. Girls who reported more peer popularity efforts sexted more and had lower self-esteem at baseline than their peers. The association between family situation and striving for peer popularity was significant, albeit of small size, $r=.17, \mathrm{SE}=.03, p$ $=.02$.

\section{DISCUSSION}

Sexting has become a topic of increased interest and concern among researchers, clinicians, and the general public. Although research on adolescent sexting and psychological well-being, largely cross-sectional in design, has been inconsistent, parental and societal concerns about purportedly adverse outcomes—-particularly girls' self-sexualization and increased vulnerability to sexual abuse — often dominate the public discourse about sexting (Albury, 2015). The current study aimed to append the literature and inform the popular understanding of the phenomenon by exploring patterns of sexting in a longitudinal panel sample of female Croatian adolescents. Using a longitudinal design with data spanning a 20-month period, we assessed links between sexting and two indicators of psychological well-being to better inform concerns about 
adolescent sexting. Although we observed an increase in sexting during the transition from middle to late adolescence, this growth was unrelated to changes in psychological well-being. Expectedly, adverse family environment was systematically related to participants' sexting and psychological well-being. Adolescent girls who reported a more adverse family climate also reported more sexting — both initially and over time — and lower levels of psychological wellbeing at baseline. Proclivity to seeking peer popularity was also related to more sexting and lower self-esteem, but only initially.

The existing literature on sexting behavior has been largely correlational in nature (Kosenko et al., 2017). While these findings have been important and informative to understanding patterns of sexting behavior, research has reported inconsistent findings regarding psychological well-being and mental health outcomes associated with sexting. This may be a result of variation in methodological approaches and measurement of both sexting and psychological well-being. One critique of the largely correlational sexting literature has been that previous research has been unable to disentangle the ongoing debates about whether the psychosocial consequences of sexting leads to adverse psychological well-being, or whether preexisting states of psychological vulnerability lead to or co-occur alongside potentially risky sexting behavior.

The longitudinal results of the current study suggest that the dynamics of adolescent girls' sexting in the period between middle and late adolescence is unrelated to their psychological well-being. Sexting may in fact be a part of contemporary sexual development and related explorations and not necessarily a threat to adolescents' development and psychological wellbeing. Rather than the act of sending sexts itself being problematic, it may be those exceptional cases involving the nonconsensual sharing and distribution of sexts that tend to result in the 
greatest likelihood for negative legal, social, and psychological outcomes (e.g., Garcia et al., 2016).

The relatively small but significant baseline relationship between sexting and internalizing problems observed in this study points to a possibility of a dynamic association in an earlier developmental phase. This is in accord with a recent meta-analytic finding that the size of association between adolescents' sexting and internalizing problems decreased with age (Mori et al., 2019). Given sexual double standards, including the gendered sexual double bind (of girls being both sexualized and stigmatized for being sexual; Tolman, 2002), it is possible that some girls characterized by lower self-esteem and negative mood may find that sexting behavior may be a way to seek external validation. Thus, in adolescent girls sexting may be a responsive behavior to lower psychological well-being, but one that comes with potential risks (i.e., shaming, bullying, sexualizing) that could potentially further increase vulnerability to adverse psychological outcomes. This requires additional theoretical and empirical exploration, given existing findings of relatively high rates of depression among female adolescents, which is likely in part fueled by the sexual socialization of (young) women throughout much of the modern world (Heywood and Garcia, 2018). Future research should also address the role of developmentally-specific factors. Compared to older adolescents, younger girls may be less prepared and skilled to deal with emotional and social implications of sexting. Furthermore, younger adolescents may be more vulnerable to peer pressure to sext, to anonymous adults' online requests, as well as to being blackmailed following sexting.

Theory suggests both parental and peer influences impact sexual behavior in adolescence. According to our findings, both adverse family environment and striving for peer popularitywhich were significantly interrelated — increased the likelihood of sexting in middle adolescence. However, only family environment, which was measured as a time-varying construct, was found 
associated with growth in sexting over the period under observation. Adverse family environment was also consistently linked to the two indicators of psychological health, particularly with internalizing problems, which is consistent with the literature (see, for example, Schleider \& Weisz, 2017). Although not directly assessed in this study, negative family environment may be a developmentally-specific vulnerability factor for sexting-related problems. Future research should address this in panels with wider age differences.

The current study has several educational and clinical implications. In most cases sexting is unrelated to adverse changes in girls' psychological well-being during middle to late adolescence. When frequent sexting and diminished psychological well-being are observed at the same time, educational specialists and clinicians should — in addition to addressing possible peer pressure to sext (Bianchi, Morelli, Baiocco and Chirumbolo, 2019) - pay attention to the adolescent's family dynamics, which may underlie both phenomena. Considering that associations between sexting and lower psychological well-being lack clear directionality, a careful consideration of likely temporal sequence would be essential for efficient intervention.

\section{Study Limitations and Future Directions}

Apart from the current study's strengths — such as a 5-wave longitudinal assessment spanning over 20 months, a relatively large panel sample of adolescents from a Southeast European country, and the use of a robust analytical approach (LGCM) — a few limitations should also be noted. First, it cannot be ruled out that the observed attrition bias (underrepresentation of adolescent girls with lower academic achievement) affected some of our findings. Second, while the current findings report on two important measures of psychological well-being consistent with theory and past research, future work may wish to expand this to include a wider range of psychological health and well-being measurements. Third, our study did not examine whether the experience of having one's sext shared without consent, or of having been shamed or bullied for 
sexting are relevant mediators of the key association. Fourth, the extent to which the reported findings are culture-specific remains unknown. Multi-national and cross-cultural assessment of associations between sexting and adolescent psychological well-being is an important task for future research, particularly due to a growing international popularity of the practice of sexting (West et al. 2014; Olatunde and Balogun 2017).

\section{CONCLUSIONS}

Controlling for parental and peer influences, we found no significant association between the changes in sexting and changes in self-esteem nor with depression and anxiety among female Croatian adolescents over a period of almost two years. The findings support the notion that sexting has become an aspect of sexual exploration and development for many adolescents, rather than a psychological health risk. This sharply contrasts with recent legal practices in several countries of charging some teenagers who sexted for producing, possessing and distributing child pornography and/or sexual harassment (Angelides, 2013; Hasinoff, 2013), Croatia included. The fact that adolescent girls face unique challenges in their sexual expression around stigma, social pressure, and body confidence offers no support for a moral panic, but calls for digital media literacy and comprehensive sexuality education programs that would address risks potentially associated with sexting, while at the same time respecting adolescents' sexual expression and sexual well-being (Fortenberry, 2016). 


\section{REFERENCES}

Albury K (2015) Selfies, sexts and ‘sneaky hats': Young people’s understandings of gendered Practices of self-representation. International Journal of Communication 9: 1734-1745. DOI: $1932-8036 / 2015 F E A 0002$.

Angelides S (2013) ‘Technology, hormones, and stupidity': The affective politics of teenage sexting. Sexualities 16(5-6): 665-689. DOI: 10.1177/1363460713487289.

Baumgartner SE, Sumter SR, Peter J, et al. (2014) Does country context matter? Investigating the predictors of teen sexting across Europe. Computers in Human Behavior 34: 157-164. DOI: 10.1016/j.chb.2014.01.041.

Benotsch EG, Snipes DJ, Martin AM, et al. (2013) Sexting, substance use, and sexual risk behavior in young adults. Journal of Adolescent Health 52(3): 307-313. DOI: 10.1016/j.jadohealth.2012.06.011.

Best P, Manktelow R and Taylor B (2014) Online communication, social media and adolescent wellbeing: A systematic narrative review. Children and Youth Services Review 41. Elsevier Ltd: 27-36. DOI: 10.1016/j.childyouth.2014.03.001.

Bianchi D, Morelli M, Baiocco R, Cattelino E, et al. (2019) Family functioning patterns predict teenage girls' sexting. International Journal of Behavioral Development 43(6). SAGE Publications Ltd: 507-514. DOI: 10.1177/0165025419873037.

Bianchi D, Morelli M, Baiocco R and Chirumbolo A (2019) Individual differences and developmental trends in sexting motivations. Current Psychology. Springer New York LLC: 1-10. DOI: 10.1007/s12144-019-00398-4.

Boutakidis I and Lieber E (2017) Parent, Peers, and Adolescent Outcomes: Interactions and Cultural Variations. In: Selin H (ed.) Parenting across Cultures: Childrearing, Motherhood 
and Fatherhood in Non-Western Cultures: The History of Non-Western Science 7.

Netherlands: Springer, pp. 435-444.

Brechwald WA and Prinstein MJ (2011) Beyond homophily: A decade of advances in understanding peer influence processes. Journal of Research on Adolescence 21(1): 166179. DOI: $10.1111 /$ j.1532-7795.2010.00721.x.Beyond.

Bronfenbrenner U (1989) Ecological systems theory. Annals of Child Development 6: 187-249. Byrne BM (2010) Structural Equation Modeling with AMOS: Basic Concepts, Applications, and Programming. Routledge. DOI: 10.4324/9781410600219.

Caprara GV, Regalia C and Bandura A (2002) Longitudinal Impact of Perceived Self-Regulatory Efficacy on Violent Conduct. European Psychologist 7(1): 63-69. DOI: 10.1027//10169040.7.1.63.

Cénat JM, Hébert M, Blais M, et al. (2014) Cyberbullying, psychological distress and self-esteem among youth in Quebec schools. Journal of Affective Disorders 169: 7-9. DOI: 10.1016/j.jad.2014.07.019.

Cooper K, Quayle E, Jonsson L, et al. (2016) Adolescents and self-taken sexual images: A review of the literature. Computers in Human Behavior. DOI: 10.1016/j.chb.2015.10.003. Curran PJ, Obeidat K and Losardo D (2010) Twelve frequently asked questions about growth curve modeling. Journal of Cognitive Development 11(2): 121-136. DOI: 10.1080/15248371003699969.Twelve.

Currin JM, Jayne CN, Hammer TR, et al. (2016) Explicitly pressing send: Impact of sexting on relationship satisfaction. American Journal of Family Therapy 44(3). Routledge: 143-154. DOI: $10.1080 / 01926187.2016 .1145086$.

Dake JA, Price J, Maziarz L, et al. (2012) Prevalence and correlates of sexting behaviorin adolescents. American Journal of Sexuality Education 7(1): 1-15. 
de Graaf H, van de Schoot R, Woertman L, et al. (2012) Family cohesion and romantic and sexual initiation: A three wave longitudinal study. Journal of Youth and Adolescence 41(5): 583-592. DOI: 10.1007/s10964-011-9708-9.

Deptula DP, Henry DB and Schoeny ME (2010) How can parents make a difference? Longitudinal associations with adolescent sexual behavior. Journal of Family Psychology 24(6): 731-739. DOI: 10.1037/a0021760.

Dir AL, Cyders MA and Coskunpinar A (2013) From the bar to the bed via mobile phone: A first test of the role of problematic alcohol use, sexting, and impulsivity-related traits in sexual hookups. Computers in Human Behavior 29(4): 1664-1670. DOI: 10.1016/j.chb.2013.01.039.

Döring N (2014) Consensual sexting among adolescents: Risk prevention through abstinence education or safer sexting? Cyberpsychology 8(1). DOI: 10.5817/CP2014-1-9.

Drouin M (2017) Sexting. In: Nixon PG and Düsterhöft IK (eds) Sex in the Digital Age. Routledge, pp. 68-77.

Drouin M, Ross J and Tobin E (2015) Sexting: A new, digital vehicle for intimate partner aggression? Computers in Human Behavior 50: 197-204. DOI: 10.1016/j.chb.2015.04.001. Englander E (2012) Low Risk Associated With Most Teenage Sexting: A Study Of 617 18-YearOlds. Massachusetts Aggression Reduction Center 5(July): 1-12.

Festl R, Reer F and Quandt T (2019) Online sexual engagement and psychosocial well-being: The mediating role of sexual victimization experiences. Computers in Human Behavior 98. Elsevier Ltd: 102-110. DOI: 10.1016/j.chb.2019.04.010.

Fortenberry JD (2016) Adolescent Sexual Well-being in the 21st Century. Journal of Adolescent Health 58(1). Elsevier: 1-2. DOI: 10.1016/j.jadohealth.2015.10.250.

Gámez-Guadix M and Mateos-Pérez E (2019) Longitudinal and reciprocal relationships between 
sexting, online sexual solicitations, and cyberbullying among minors. Computers in Human Behavior 94. Elsevier Ltd: 70-76. DOI: 10.1016/j.chb.2019.01.004.

Garcia JR, Gesselman AN, Siliman SA, et al. (2016) Sexting among singles in the USA:

Prevalence of sending, receiving, and sharing sexual messages and images. Sexual Health 13(5): 428-435. DOI: $10.1071 / \mathrm{SH} 15240$.

Gordon-Messer D, Bauermeister JA, Grodzinski A, et al. (2013) Sexting among young adults. Journal of Adolescent Health 52(3): 301-306. DOI: 10.1016/j.jadohealth.2012.05.013.

Graham JW (2012) Missing Data: Analysis and Design. New York: Springer. DOI: 10.1007/978$1-4614-4018-5$.

Hasinoff AA (2013) Sexting as media production: Rethinking social media and sexuality. New Media and Society 15(4): 449-465. DOI: 10.1177/1461444812459171.

Henderson L (2011) Sexting and Sexual Relationships Among Teens and Young Adults. McNair Scholars Research Journal 7(1).

Heywood LL and Garcia JR (2018) Integrating evolutionary affective neuroscience and feminism in gender research. In: Nancy Dess, Jeanne Marecek and LB (ed.) Gender, Sex, \& Sexualities: Psychological Perspectives. New York: Oxford University Press, pp. 295-317. DOI: $10.1093 /$ oso/9780190658540.003.0013.

Houck CD, Barker D, Rizzo C, et al. (2014) Sexting and Sexual Behavior in At-Risk Adolescents. Pediatrics 133(2): e276-e282. DOI: 10.1542/peds.2013-1157.

Hudson HK and Fetro J V. (2015) Sextual activity: Predictors of sexting behaviors and intentions to sext among selected undergraduate students. Computers in Human Behavior 49: 615-622. DOI: $10.1016 /$ j.chb.2015.03.048.

Jonsson LS, Bladh M, Priebe G, et al. (2015) Online sexual behaviours among Swedish youth: associations to background factors, behaviours and abuse. European Child and Adolescent 
Psychiatry 24(10): 1245-1260. DOI: 10.1007/s00787-015-0673-9.

Klein V, Becker I and Štulhofer A (2018) Parenting, Communication about Sexuality, and the Development of Adolescent Womens' Sexual Agency: A Longitudinal Assessment. Journal of Youth and Adolescence 47(7). Springer US: 1486-1498. DOI: 10.1007/s10964-018-0873y.

Klettke B, Hallford DJ and Mellor DJ (2014) Sexting prevalence and correlates: A systematic literature review. Clinical Psychology Review 34(1). Elsevier Ltd: 44-53. DOI: 10.1016/j.cpr.2013.10.007.

Kolesarić V and Ajduković M (eds) (2003) Etički Kodeks Istraživanja s Djecom. Zagreb: Vijeće za djecu Vlade Republike Hrvatske.

Kosenko K, Luurs G and Binder AR (2017) Sexting and Sexual Behavior, 2011-2015: A Critical Review and Meta-Analysis of a Growing Literature. Journal of Computer-Mediated Communication: 2011-2015. DOI: 10.1111/jcc4.12187.

Kroenke K, Spitzer RL, Williams JBW, et al. (2009) An Ultra-Brief Screening Scale for Anxiety and Depression: The PHQ-4. Psychosomatics 50(6): 613-621. DOI: 10.1176/appi.psy.50.6.613.

Kuehner C (2017) Why is depression more common among women than among men? The Lancet Psychiatry. DOI: 10.1016/S2215-0366(16)30263-2.

Landripet I, Štulhofer A and Baćak V (2011) Changes in human immunodeficiency virus and sexually transmitted infections- related sexual risk taking among young Croatian adults : 2005 and 2010 population-based surveys. Croatian Medical Journal 52(4): 458-468. DOI: $10.3325 / \mathrm{cmj} .2011 .52 .458$.

Lippman, J. R. \& Campbell SW (2014) Damned if you do, damned if you don't... if you're a girl: Relational and normative contexts of adolescent sexting in the United States. Journal of 
Children and Media 8(4): 371-386.

Little TD (2013) Longitudinal Structural Equation Modeling. New York: Guilford Press.

Lucić M, Baćak V and Štulhofer A (2019) The role of peer networks in adolescent pornography use and sexting in Croatia. Journal of Children and Media. Routledge: 1-18. DOI: $10.1080 / 17482798.2019 .1637356$.

Luijkx, R., Halman, L., Sieben, I., Brislinger, E., \& Quandt M, Luijkx R, Halman L, et al. (2016) European Values in Numbers. Leiden: Brill. DOI: 10.1163/9789004328525.

Maheux AJ, Evans R, Widman L, et al. (2020) Popular peer norms and adolescent sexting behavior. Journal of Adolescence 78. Academic Press: 62-66. DOI: 10.1016/j.adolescence.2019.12.002.

Marinović Jerolimov D and Ančić B (2014) Religioznost i stavovi prema seksualnosti i braku odrasle populacije u Hrvatskoj. Društvena istraživanja 23(1): 111-132. DOI: $10.5559 / \mathrm{di} 23.1 .06$.

Marinović Jerolimov D and Jokić B (2010) Religion and Youth in Croatia. In: Giordan G (ed.) Annual Review of the Sociology of Religion, Volume 1: Youth and Religion. Leiden: Brill. McArdle JJ and Grimm KJ (2010) Five steps in latent curve and latent change score modeling with longitudinal data. In: van Montfort K, Oud J, and Sattora A (eds) Longitudinal Research with Latent Variables. New York: Springer, pp. 245-273. DOI: 10.1007/978-3642-11760-2_8.

Mojtabai R, Olfson M and Han B (2016) National Trends in the Prevalence and Treatment of Depression in Adolescents and Young Adults. Pediatrics 138(6). American Academy of Pediatrics: e20161878. DOI: 10.1542/peds.2016-1878.

Montgomery SC, Donnelly M, Bhatnagar P, et al. (2020) Peer social network processes and adolescent health behaviors: A systematic review. Preventive Medicine. Academic Press Inc. 
DOI: 10.1016/j.ypmed.2019.105900.

Mori C, Temple JR, Browne D, et al. (2019) Association of sexting with sexual behaviors and mental health among adolescents. JAMA Pediatrics. DOI:

10.1001/jamapediatrics.2019.1658.

Mounts NS (2002) Parental management of adolescent peer relationships in context: The role of parenting style. Journal of Family Psychology 16(1): 58-69. DOI: 10.1037//08933200.16.1.58.

Muthén BO and Curran PJ (1997) General longitudinal modeling of individual differences in experimental designs: A latent variable framework for analysis and power estimation. Psychological Methods 2(4): 371-402. DOI: 10.1037/1082-989X.2.4.371.

O’Connor K, Drouin M, Yergens N, et al. (2017) Sexting Legislation in the United States and Abroad: A Call for Uniformity. International Journal of Cyber Criminology 11(2): 218245.

Olatunde O and Balogun F (2017) Sexting: Prevalence, Predictors, and Associated Sexual Risk Behaviors among Postsecondary School Young People in Ibadan, Nigeria. Frontiers in Public Health 5. DOI: 10.3389/fpubh.2017.00096.

Orenstein P (2016) Girls and Sex: Navigating the Complicated New Landscape. New York: Harper Collins.

Preacher KJ, Wicham AL, MacCallum RC, et al. (2008) Latent Growth Curve Modeling. Thousand Oaks, CA, CA: Sage.

Puzek I, Štulhofer A and Božičević I (2012) Is religiosity a barrier to sexual and reproductive health? Results from a population-based study of young Croatian adults. Archives of Sexual Behavior 41: 1497-1505. DOI: 10.1007/s10508-012-9924-8.

Rey R Del, Ojeda M, Casas JA, et al. (2019) Sexting among adolescents: The emotional impact 
and influence of the need for popularity. Frontiers in Psychology 10(AUG). Frontiers Media S.A. DOI: 10.3389/fpsyg.2019.01828.

Ringrose J, Harvey L, Gill R, et al. (2013) Teen girls, sexual double standards and 'sexting': Gendered value in digital image exchange. Feminist Theory 14(3). SAGE PublicationsSage UK: London, England: 305-323. DOI: 10.1177/1464700113499853.

Santor DA, Messervey D and Kusumakar V (2000) Measuring peer pressure, popularity, and conformity in adolescent boys and girls: Predicting school performance, sexual attitudes, and substance abuse. Journal of Youth and Adolescence 29(2). Kluwer Academic Publishers-Plenum Publishers: 163-182. DOI: 10.1023/A:1005152515264.

Schleider JL and Weisz JR (2017) Family process and youth internalizing problems: A triadic model of etiology and intervention. Development and Psychopathology 29(1): 273-301. DOI: $10.1017 / \mathrm{S} 095457941600016 \mathrm{X}$

Smahel D, Machackova H, Mascheroni G, et al. (2020) EU Kids Online 2020: Survey Results from 19 Countries. DOI: 10.21953/lse.47fdeqj01ofo.

Stark KD and Laurent J (2001) Joint factor analysis of the Children's Depression Inventory and the Revised Children's Manifest Anxiety Scale. Journal of Clinical Child \& Adolescent Psychology 30(4): 552-567. DOI: 10.1207/S15374424JCCP3004_11.

Strassberg DS, McKinnon RK, Sustaíta MA, et al. (2013) Sexting by high school students: An exploratory and descriptive study. Archives of Sexual Behavior 42(1): 15-21. DOI: $10.1007 / \mathrm{s} 10508-012-9969-8$.

Štulhofer A, Šoh D, Jelaska N, et al. (2011) Religiosity and sexual risk behavior among Croatian college students, 1998-2008. Journal of Sex Research 48(4): 360-71. DOI: $10.1080 / 00224499.2010 .494257$.

Sullivan CJ (2006) Early Adolescent Delinquency: Assessing the Role of Childhood Problems, 
Family Environment, and Peer Pressure. Youth Violence and Juvenile Justice 4(4): 291-313. DOI: $10.1177 / 1541204006292656$.

Symons K, Ponnet K, Walrave M, et al. (2018) Sexting scripts in adolescent relationships: Is sexting becoming the norm? New Media and Society 20(10): 3836-3857. DOI: $10.1177 / 1461444818761869$.

Temple JR, Le VD, van den Berg P, et al. (2014) Brief report: Teen sexting and psychosocial health. Journal of Adolescence 37(1). Elsevier Ltd: 33-36. DOI: 10.1016/j.adolescence.2013.10.008.

The National Campaign to Prevent Teen and Unplanned Pregnancy (2008) Sex and tech: Results from a survey of teens and young adults.

Tolman DL (2002) Dillemas of Desire: Teenage Girls Talk about Sexuality. Harvard University Press.

Tomić I, Burić J and Štulhofer A (2018) Associations Between Croatian Adolescents' Use of Sexually Explicit Material and Sexual Behavior: Does Parental Monitoring Play a Role? Archives of Sexual Behavior 47(6): 1881-1893. DOI: 10.1007/s10508-017-1097-z.

van Oosten JMF and Vandenbosch L (2017) Sexy online self-presentation on social network sites and the willingness to engage in sexting: A comparison of gender and age. Journal of Adolescence 54. Academic Press: 42-50. DOI: 10.1016/j.adolescence.2016.11.006.

Van Ouytsel J, Van Gool E, Ponnet K, et al. (2014) Brief report: The association between adolescents' characteristics and engagement in sexting. Journal of Adolescence 37(8): 13871391. DOI: $10.1016 /$ j.adolescence.2014.10.004.

Van Ouytsel J, Walrave M, Ponnet K, et al. (2015) The Association Between Adolescent Sexting, Psychosocial Difficulties, and Risk Behavior. The Journal of School Nursing 31(1): 54-69. DOI: $10.1177 / 1059840514541964$. 
Van Ouytsel J, Walrave M and Ponnet K (2019) An exploratory study of sexting behaviors among heterosexual and sexual minority early adolescents. Journal of Adolescent Health 65(5). Elsevier USA: 621-626. DOI: 10.1016/j.jadohealth.2019.06.003.

Walrave M, Heirman W and Hallam L (2014) Under pressure to sext? Applying the theory of planned behaviour to adolescent sexting. Behaviour and Information Technology 33(1): 8597. DOI: 10.1080/0144929X.2013.837099.

West JH, Lister CE, Hall PC, et al. (2014) Sexting among Peruvian adolescents. BMC Public Health 14(1). BioMed Central: 811. DOI: 10.1186/1471-2458-14-811. 
Table 1. Descriptive Information about and Cross-Correlations Between the Key Indicators

\begin{tabular}{|c|c|c|c|c|c|c|c|c|c|c|c|c|c|c|c|c|}
\hline & 2 & 3 & 4 & 5 & 6 & 7 & 8 & 9 & 10 & 11 & 12 & 13 & 14 & 15 & $\begin{array}{c}M \\
(S D)\end{array}$ & Range \\
\hline (1) Sexting T1 & $.64 * *$ & $.57^{* *}$ & $.52^{* *}$ & $.48^{* *}$ & $.16^{* *}$ & $.16^{* *}$ & $.17^{* *}$ & $.14 * *$ & $.15^{* *}$ & -.04 & -.01 & -.01 & -.04 & -02 & $\begin{array}{l}4.27 \\
(2.13)\end{array}$ & $3-15$ \\
\hline (2) Sexting T2 & & $.64 * *$ & $.54 * *$ & $.43^{* *}$ & $.17^{* *}$ & $.22^{* *}$ & $.17 * *$ & $.13^{* *}$ & $14^{* *}$ & -.07 & -.02 & -.00 & .02 & -.05 & $\begin{array}{c}4.06 \\
(2.05)\end{array}$ & $3-15$ \\
\hline (3) Sexting T4 & & & $.62 * *$ & $.59^{* *}$ & $.20^{* *}$ & $.18^{* *}$ & $.13^{* *}$ & $.16^{* *}$ & $.14 * *$ & -.05 & -.06 & -.02 & -.02 & .00 & $\begin{array}{c}4.28 \\
(2.30)\end{array}$ & $3-15$ \\
\hline (4) Sexting T4 & & & & $.69^{* *}$ & $.13 * *$ & $.12^{* *}$ & $.17 * *$ & $.11^{* *}$ & $.14 * *$ & -.04 & -.02 & .05 & .00 & -.01 & $\begin{array}{c}4.35 \\
(2.44)\end{array}$ & $3-15$ \\
\hline (5) Sexting T5 & & & & & $.17^{* *}$ & $.15^{* *}$ & $.10^{*}$ & $.09 *$ & $.09^{*}$ & -.06 & -.07 & -.02 & -.04 & -.03 & $\begin{array}{c}4.52 \\
(2.59)\end{array}$ & $3-15$ \\
\hline (6) Depression and anxiety T1 & & & & & & $.64^{* *}$ & $.52 * *$ & $.48^{* *}$ & $.47^{* *}$ & $-.30^{* *}$ & $-.37 * *$ & $-.24 * *$ & $-.27 * *$ & $-.24 * *$ & $\begin{array}{c}9.57 \\
(3.36)\end{array}$ & $4-16$ \\
\hline (7) Depression and anxiety T2 & & & & & & & $.58^{* *}$ & $.54 * *$ & $.54 * *$ & $-.33 * *$ & $-.34 * *$ & $-.26^{* *}$ & $-.30^{* *}$ & $-.28 * *$ & $\begin{array}{c}8.89 \\
(3.17)\end{array}$ & $4-16$ \\
\hline (8) Depression and anxiety T3 & & & & & & & & $.61^{* *}$ & $.60^{* *}$ & $-.30^{* *}$ & $-.31 * *$ & $-.34 * *$ & $-.32 * *$ & $-.32 * *$ & $\begin{array}{c}8.40 \\
(2.95)\end{array}$ & $4-16$ \\
\hline (9) Depression and anxiety T4 & & & & & & & & & $.55^{* *}$ & $-.23 * *$ & $-.27^{* *}$ & $-.25 * *$ & $-.36^{* *}$ & $-.31^{* *}$ & $\begin{array}{c}8.69 \\
(3.07)\end{array}$ & $4-16$ \\
\hline (10) Depression and anxiety T5 & & & & & & & & & & $-.27^{* *}$ & $-.29 * *$ & $-.23 * *$ & $-.28^{* *}$ & $-.36^{* *}$ & $\begin{array}{c}8.35 \\
(2.95)\end{array}$ & $4-16$ \\
\hline
\end{tabular}


(11) Self-esteem T1

(12) Self-esteem T2

(13) Self-esteem T3

(14) Self-esteem T4

(15) Self-esteem T5

$.72 *$

$\begin{array}{ccccc}.64 * * & .67 * * & .62 * * & 15.20 & 4-20 \\ & & & (2.95) & \\ .71 * * & .69 * * & .65 * * & 15.54 & 4-20 \\ & & & (2.89) & \\ & .71 * * & .70 * * & 15.45 & 6-20 \\ & & (2.69) & \\ & .74 * * & 15.78 & 4-20 \\ & & (2.71) & \\ & & 15.85 & 7-20 \\ & & (2.79) & \end{array}$

$* p<.05, * * p<.01$ 
Table 2. Unconditional and Conditional Multi-Domain Latent Growth Model Estimates and Fit Indices $(n=859)$

\section{Unconditional model Conditional model}

Sexting

Mean intercept $4.21(\mathrm{SE}=.07)^{*} \quad 4.21(\mathrm{SE}=.07)^{*}$

Variance in individual intercepts

$2.88(\mathrm{SE}=.18)^{*} \quad 2.68(\mathrm{SE}=.17)^{*}$

Mean slope

$0.33(\mathrm{SE}=.08)^{*} \quad 0.33(\mathrm{SE}=.08)^{*}$

Variance in individual slopes

$2.27(\mathrm{SE}=.34)^{*} \quad 2.26(\mathrm{SE}=.34)^{*}$

Depression/Anxiety

Mean intercept $\quad 9.58(\mathrm{SE}=.12)^{*} \quad 9.58(\mathrm{SE}=.12)^{*}$

Variance in individual intercepts $\quad 8.22(\mathrm{SE}=.57)^{*} \quad 6.76(\mathrm{SE}=.53)^{*}$

Mean slope $\quad-1.20(\mathrm{SE}=.12)^{*} \quad-1.19(\mathrm{SE}=.12)^{*}$

Variance in individual slopes $\quad 4.03(\mathrm{SE}=.61)^{*} \quad 3.65(\mathrm{SE}=.59)^{*}$

Self-esteem

Mean intercept $15.31(\mathrm{SE}=.09)^{*} \quad 15.30(\mathrm{SE}=.09)^{*}$

Variance in individual intercepts $\quad 6.22(\mathrm{SE}=.38)^{*} \quad 5.69(\mathrm{SE}=.36)^{*}$

Mean slope $\quad 0.03(\mathrm{SE}=.01)^{*} \quad 0.03(\mathrm{SE}=.01)^{*}$

Variance in individual slopes $\quad 0.01(\mathrm{SE}=.00)^{*} \quad 0.00(\mathrm{SE}=.00)^{*}$

\begin{tabular}{lll}
\hline$\chi^{2}(\mathrm{df})$ & $263.51(99)$ & $442.90(205)$
\end{tabular}

$\mathrm{TLI} / \mathrm{CFI}$

$.960 / .967$

$.955 / .964$

RMSEA $(90 \% \mathrm{CI})$

$.041(.035-.047) \quad .034(.030-.038)$

$* p<.001$ 
Figure 1. Associations between Sexting, Depression and Anxiety, and Self-Esteem in Female Croatian Adolescents $(n=859)$ over a Period of 20 Months

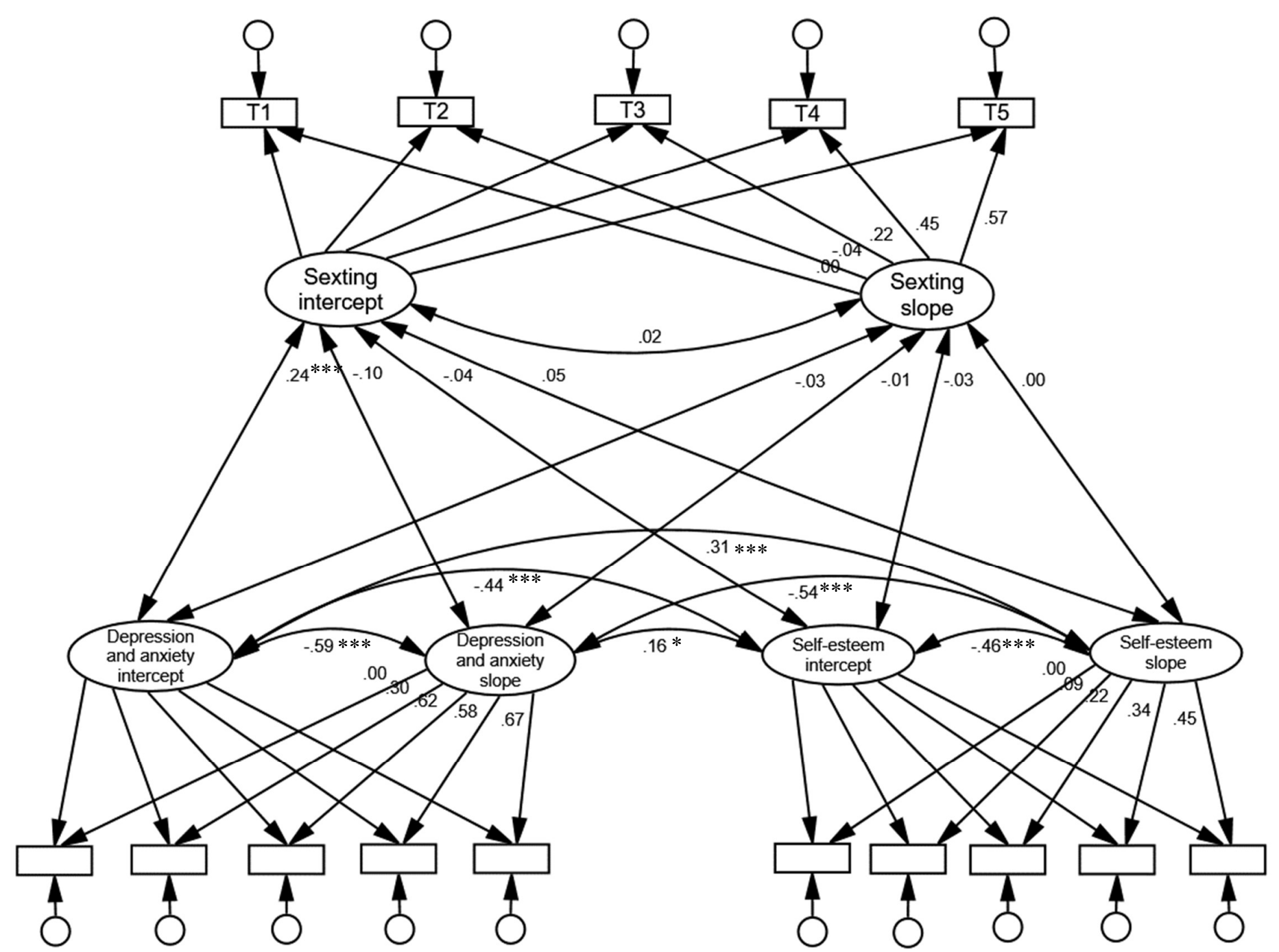

Model fit: $\chi^{2}\left({ }_{(99)}=263.51, \mathrm{TLI}=.960, \mathrm{CFI}=.967, \mathrm{RMSEA}=.041(90 \% \mathrm{CI}=.035-.047) ;{ }^{*} p<.05, * * p<.01,{ }^{* * *} p<.001\right.$ 